\title{
Method for Evaluating a Building Information Model
}

\author{
Ádám Tamás Kovács ${ }^{1 *}$, András Micsik² \\ 1 Department of Architectural Geometry and Informatics, \\ Budapest University of Technology and Economics \\ H-1111, Budapest, Múegyetem rkp. 3, Hungary \\ 2 Department of Distributed Systems, \\ Institute for Computer Science and Control, Hungarian Academy of Sciences, \\ H-1111, Budapest, Lágymányosi u. 11. \\ * Corresponding author, e-mail: kovacsadam@arch.bme.hu
}

Received: 22 May 2018, Accepted: 31 January 2019, Published online: 11 April 2019

\begin{abstract}
This paper discusses a method for evaluating building information models from the point of view of different disciplines. The ultimate goal is to provide a methodology for decision-makers on an Architecture, Engineering, and Construction (AEC) project, where they can follow the status and performance of the BIM model at each project milestone, from different aspects, in a comparable manner. This methodology requires an evaluation method that aggregates data input by the designers. Interpreting BIM models is complex - multidimensional, in fact, considering the meta-information added to it. Therefore, the aggregation process is not trivial and may differ in several cases. We build up multi-dimensional diagrams to chart the possible factors of the evaluation, besides introducing aggregation rules and visualizations. For such a method, it was essential to analyze BIM ontologies in order to establish a precise definition for each concept: milestones, building parts, indicator metrics, etc. We describe an example project workflow where our method works in theory, while we give a practical solution how to add the evaluation data to the BIM model with CAAD software.
\end{abstract}

\section{Keywords}

BIM, evaluation, decision-support

\section{Introduction}

Productivity in the Architecture, Engineering, and Construction field lags behind the other branches of industry (Fig. 1) although the technology is already developed enough to be able to handle the industry's needs. What we need is a new methodology to make the workflows in construction projects more efficient, as well as improving the overall quality of buildings.

At the same time, since the human race over-exploits the resources of the globe, industry is motivated, to some extent, to produce optimal buildings that minimize cost and the ecological footprint. Throughout the process, there are so many requirements and regulations from different points of view that it became overwhelmingly complex, and decision-makers cannot properly see the total picture. This may result in two outcomes.

The first is that the architect team designs the shape of the building and then hands the plans over to the designers in various disciplines, telling them to solve the building according to their areas of expertise. This is the usual case in Hungary, according to research [1] among the Hungarian architect studios. Our architect students at Budapest University of Technology and Economics conducted research by making interviews and online surveys on BIM appliance in the Hungarian AEC industry.

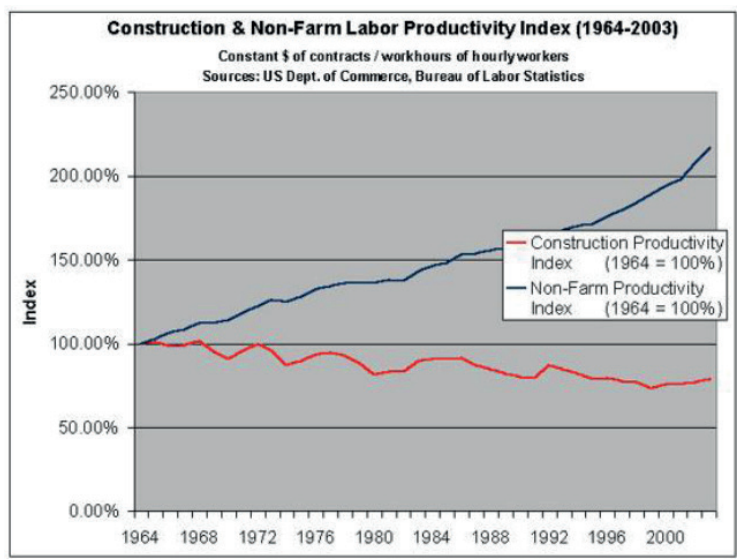

Fig. 1 Labor productivity index for US construction industry and all non-farm industries 
Since the shape of the building determines most of its performance, this is not a good solution. As Deutsch, R. expresses it, in such cases, architects are "gambling" [2].

In the second outcome, decision-makers rely a great deal on expert reports made by designers in different disciplines. These reports are usually presentations, documents, phone calls, and live meetings which are difficult to summarize. Also, since there are so many fields of expertise, it makes summarizing increasingly challenging. To solve this problem, we need a methodology which supports this process, allowing us to truly realize Transparent Design [3] and Integrated Design [4].

One conclusion from the interviews, conducted by the students with lead architects in the course of their research, [1] was the desire for a dashboard that would make it possible to view all the aggregated data of their actual projects and to take them into account when making decisions. Deutsch, R. [2] differentiates three types of this decision-making: data-enabled, data-informed, data-driven. According to his research, this provides a great benefit for architects, who stand on much firmer ground and can defend their decisions against contractors and other designers.

In order to create a methodology which contains dashboards based on data serving all the project participants in order to make better decisions, there needs to be a method for evaluating the Building Information Model. To create such a method, first, we have to define performance indicators. Second, we have to create rules for the aggregation and processing of data. Third, we have to organize the project's paths of communication well - both in terms of process and technology. Fourth, we have to build a digital knowledge base where the concepts and definitions used during the project are defined and accessible for all of the project participants.

\section{BIM definitions}

BIM originally stands for Building Information Modeling, but people tend to use this term slightly differently, as Building Information Model or Building Information Management. According to Matějkaa, P.'s research into what people think is the meaning of BIM, [5] this verifies that it is not clear at all. There are three main categories: people think of BIM as a product, as a method, or as a methodology. In this paper, we prefer understanding BIM as a methodology, as stated by Eastman et al. [6]: "BIM is a process improvement methodology that leverages data to analyze and predict outcomes throughout different phases of the building life cycle."

When a project is launched with BIM, the designers need to communicate with each other about the virtual building with 3D geometry content and other meta-information. When designers are allowed to use different software to model, this is called an OPEN BIM environment. In this case, there needs to be a common exchange file format, which the project participants can import from or export to. This is the IFC (Industry Foundation Classes), which are created by an organization called buildingSMART, a worldwide authority driving the transformation of the built asset economy through the creation and adoption of open, international standards.

During the design process, there are different milestones representing the status of the building's preparation. If the project is operating with BIM, we are talking about the virtual model's level of preparation. In order to define each of these states, the notion of LOD (Level of Development) is introduced. LOD should define the amount of detail in the 3D geometry and the richness of information in the model itself.

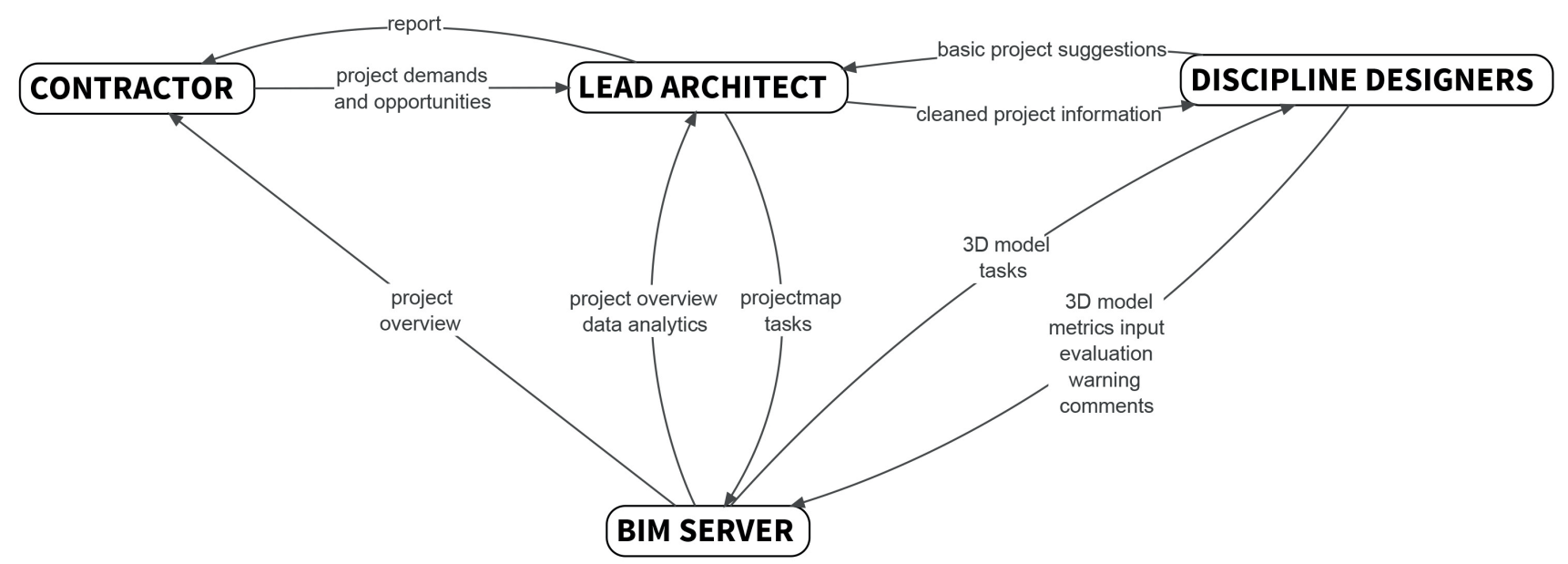

Fig. 2 The workflow of a project using Building Information Model Evaluation Method 


\section{Suggested design workflow using building information evaluation}

Since we are suggesting an evaluation method in order to realize data-driven and integrated design, we would like to show one example of a project structure where it is integrated. There may be other functioning variations as well, which could be part of our future work; yet, the aim of this article is to introduce the evaluation method itself.

In the following section, we will discuss the design workflow (Fig. 2) where a contractor trusts a general architect designer studio with the design of an approximately $5000 \mathrm{~m}^{2}$ office building. In the studio, the lead architect is responsible for the project, and he is the one making global decisions concerning the design of the building. Other architects creating the building are considered one of the discipline designers, such as, among others, HVAC engineers, civil engineers, fire engineers, etc.

The BIM server is a computer where the main database of the building is stored. It can communicate with the project participants via IFC file and via web technologies. It runs several programs, which are used by the studio (e.g., project management tool, CAAD server, etc.). Still, the most important one, from our point of view, is a dashboard service which represents the building's data.

The design process starts with the contractor briefing the lead architect about the project demands and opportunities. Then the lead architect summarizes and forwards the demands and opportunities to the discipline designers. The discipline designers give design intents and suggestions to the architects based on the project attributes for the first version of the building.

We have defined five actions that the discipline designers may take: make a 3D model, add indicator metrics to an already existing model, make an evaluation of an existing model, make a comment, and place a warning marker.

The architect team makes and sends the first version of the $3 \mathrm{D}$ model with the attached meta-information to the discipline designers. Discipline designers, according to the given milestone, assess requirements and give present performance values to items based on their field of expertise. Additionally, they even place warning markers or contribute comments as well.

All this work can be followed and checked by the lead architect, or even the contractor, at the BIM server via the Building Information Dashboard, where they see the project overview, the warnings, and the comments. They may even zoom in one part of the overview and investigate any anomalies in the building data. Afterwards, design iteration

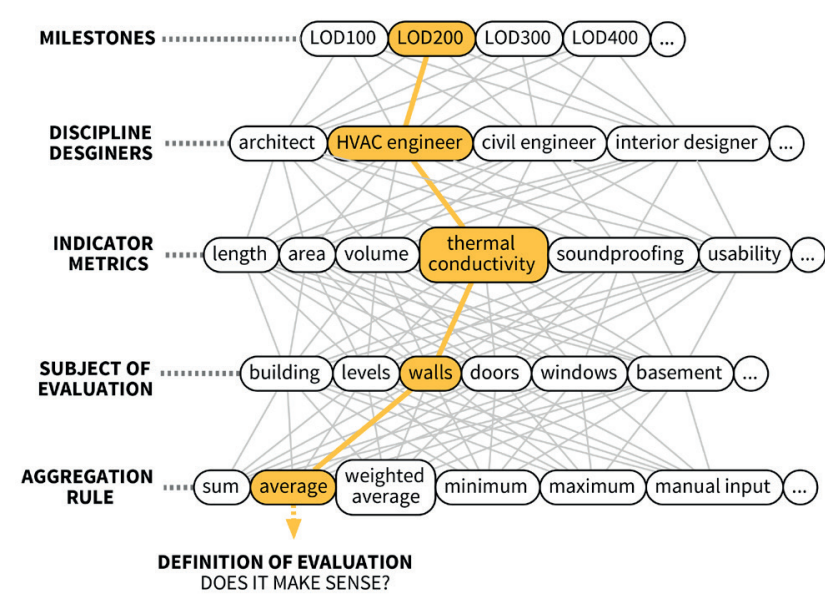

Fig. 3 Rationale analysis of evaluation in multiple dimensions

begins, when these steps are repeated with more and more details in each round. Throughout the entire workflow, the dashboard shows the actual performance of the building, so the lead architect is capable of making globally optimal decisions based on data displayed on the dashboard.

\section{Rationale analysis of evaluation}

In order to come up with an evaluation procedure, we charted the factors, which can have an effect on the evaluation. It turned out that BIM models are so complex that it can only be represented in a multi-dimensional space, and that the aggregation of data is not trivial and may differ in several cases. We detected analogies with the task of evaluating software design, and learned some techniques of evaluating digital libraries. [7] This gave us insight on how to tackle this problem in our case.

We built a web diagram to visualize the network of these factors in order to make a rationale analysis on them. The order of the factors is interchangeable. We show a particular representation of this network in Fig. 3. The point of such an analysis is that it enables one to define the procedure of a specific factor combination. Also, the lead architect can see all of the possible options that make sense and, according to the project's opportunities, he can decide which specific combinations to assign as a task to each project milestone.

\subsection{Milestone}

The first factor is the milestone. Depending on the characteristics of the project, there may be multiple milestones. These are notable points during the design process which indicate a given level of preparation, and at which point a quantity of data needs to be delivered to authorities, project stakeholders, etc. Such a milestone can be the concept plan, 
the preliminary design, the working drawing, etc. In a BIM environment, the virtual model possesses these levels of preparation which, in this case, are referred to as Level of Development (LOD) as stated in Section 2. From the evaluation point of view, the LOD level determines what input data can be evaluated. For example, if the input model is LOD 100, that means the building geometry is just a surface shell. Therefore, the evaluations which would involve the thickness of the walls in calculations do not make sense, because there is a lack of information.

\subsection{Discipline designers}

The second factor is the discipline designers. This factor determines the aspect of the evaluation. One can imagine it by looking at the model through a pair of glasses that represents a given discipline. For example, the lead architect can choose which aspects of evaluation to see - for example, the environmental aspects or the HVAC aspects of the model. It is possible that, at a given LOD, there is no need for a certain discipline designer. At LOD 100, an interior designer does not have much to say about the building, because it is just a "box" with no inner elements.

\subsection{Indicator metrics}

The third factor is indicator metrics. A metric is metainformation added to an object, an indicator that allows the object to be measured in certain dimensions by the discipline designers. This factor determines the metrics upon which evaluation should be based. For example, a building's energetics engineer, at LOD 100, would use the surface/volume ratio to evaluate the building; whereas, at LOD 200, U-values would be used, etc. In another example, the interior designer uses geometrical metrics (length, area, volume) and aesthetic points to evaluate premises, but cannot use U-value metrics during this evaluation. Hence, there is no valid connection between U-values and the interior designer on the diagram. In Section 5, we will discuss the main types of metrics in more detail.

\subsection{Subject of evaluation}

The fourth is the subject of evaluation. This factor defines the subject, the concrete notion which is the focus of the evaluation. Is the lead architect interested in the thermal performance of the whole building, or is he interested only in the thermal performance of the openings for example?

We differentiate 3 types of objects. The smallest item in the object hierarchy is an object. It can be a door, a slab, a wall, a beam, etc. On the other side of the scale is the whole building, which is the highest level in the hierarchy. Every type of object belongs to it through different connections. The third type is the object-group. There can be several principles to group objects together, from simple ones to more complex ones. In each case, we have to build the structure of the connections among the elements. An object-group can be a unit - for example, a classroom - or it can be a level of the building - for instance, the second floor - or it can be a system, for example the sprinkler system. In Section 7, we will discuss this topic in more detail.

\subsection{Aggregation rule}

The fifth is the aggregation rule. This factor determines the correct calculation for aggregating the data of objectgroups. The calculation can be a sum, an average, a minimum, etc. For example, if the lead architect would like to know the soundproofing performance of the walls globally, the aggregation rule is calculating an average value of all the walls. If he is interested in looking at the soundproofing performance of a given area, then the aggregation rule functions according to the minimum equation, since the weakest point determines the overall performance in that case. In Section 5, we will discuss this topic in more detail.

\subsection{Claim for knowledge base}

Apparently, during the evaluation process, we have to define different concepts, steps, milestones, objects, metrics, and disciplines in order to have all of the participants on the same theoretical platform, so they can comprehend the significance of the same words. Hence, a digital knowledge base and/or a dictionary is necessary to support the designers during the evaluation workflow. Zou, Y. et al. [8] Engineering and Construction came to the same conclusion from a risk management point of view after reviewing several articles on this topic. Despite all developments and efforts, in practice, studios are still waiting for a satisfying knowledge base solution.

There is an attempt to make a worldwide BIM dictionary by the BIMe Initiative [9]. This dictionary is translated into several languages, and we are currently participating as members of the Hungarian translation team to make the Hungarian version freely accessible to the AEC industry in the country.

\section{Possible Aggregation Methods of the Metrics 5.1 Types of the Evaluation Values}

We differentiate three types of values for the metrics: subjective, objective, and mixed. 


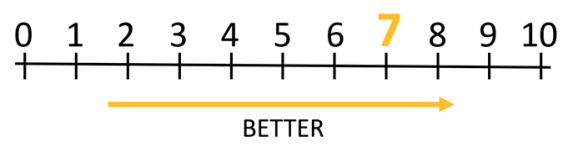

Fig. 4 Subjective scale

MIXED SCALE

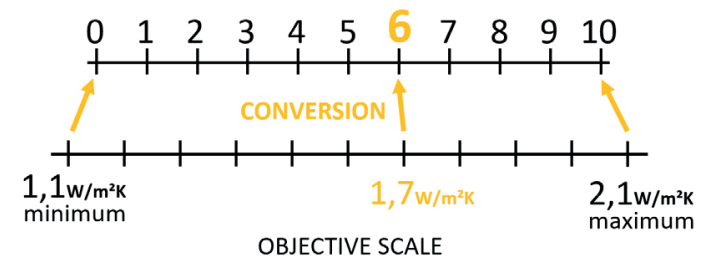

Fig. 5 The conversion from objective to mixed scale

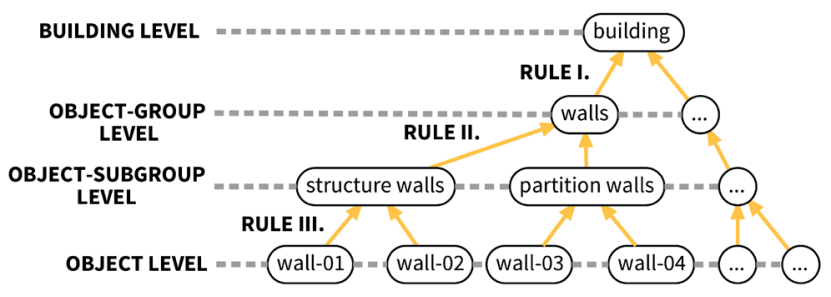

Fig. 6 Object aggregation

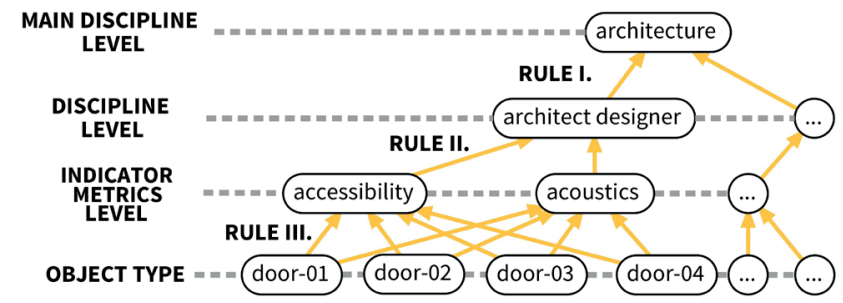

Fig. 7 Discipline aggregation

A subjective value (Fig. 4) is when the discipline designer grades an attribute of an object based on his own experience and professional opinion. The grading should be on a scale where the minimum value is the worst and the maximum value is the best solution. In our method, we used a scale of 10 , because we were considering concrete situations, and the scale of 5 did not give us enough detail. The scale of 10 provided enough without being too much. Another benefit of the scale of 10 is that it is easy to convert to the 100 scale, which then can be interpreted as percentages. In fact, designers may use their own scale if they are used to another one in their own profession, since mapping to the scale of 10 is a trivial task.

It is important to note that subjective does not mean there is no reason behind it. Instead, it means that it is up to the designers to make their own value judgments. That is why each discipline should define for itself what does the numbers between 0 and 10 mean from their point of view. For example, if the task is to evaluate the doors in terms of accessibility, the architect gives a point to each door from 0 to 10 . In this case, for instance, 0 would mean that none of the door's attributes are barrier-free, while 10 would indicate that all its attributes are barrier-free and highly ergonomic.

An objective value is a physical unit of measurement. (Fig. 5) Depending on the given discipline, this can be in decibels, $\mathrm{W} / \mathrm{m}^{2} \mathrm{~K}, \mathrm{~kg}$, etc. For example, a door may have a $35 \mathrm{~dB}$ sound transmission loss value, a $1.8 \mathrm{~W} / \mathrm{m}^{2} \mathrm{~K}$ U-value, and a $15.5 \mathrm{~kg} \mathrm{CO}$ carbon emission value. Instead of the designers inputting these values manually, this information may be derived automatically in some cases by the geometry of the object (length, perimeter, area, etc.).

A mixed value is when, during the aggregation process, we have to convert an objective value to our scale of 10 . (Fig. 5) This conversion is a subjective decision based on objective data. Therefore, we called it mixed value. In this case, the discipline designer has to find a basis of comparison and then has to map its minimum value to our scale of 0 and the maximum value to our scale of 10 . A conversion for example can be the following.

The task is to evaluate the U-value of a door and convert it. The designer checks the U-value of that exact door and may research the market to determine the best and worst U-values for doors. According the research, he can decide what U-value belongs to 0 and what U-value belongs to 10 , thus enabling him to map the exact $U$-value of the door to a scale number.

\subsection{Calculations of the aggregation rules}

If we would like to compare or sum up the data from the BIM model, or to discover anomalies in the project, we have to aggregate the values of the objects along different dimensions and categories. The relationships among the objects are so complex that this process is not trivial. We have to analyze each level of the ontologies and set a correct aggregation rule for each of them.

We discovered there are two types of aggregation: discipline and object aggregation. The object aggregation (Fig. 6) is along a chosen discipline, where we want an aggregated view of a chosen metric. It is, for example, when we aggregate the usability value of objects to object-groups (e.g., building elements) and the values of object-groups to the building level, which is the top level in the hierarchy. Discipline aggregation (Fig. 7) is along one level of the hierarchy (e.g., doors). This occurs when we aggregate the sub-discipline values of objects to discipline values, then to main discipline categories. 
We have taken into account the possible aggregation rules based on practical reasons. These are the sum function, the average function, the weighted average function, the minimum function, and the maximum function. As far as subjective and mixed values, the listed equations will probably suit our needs in most cases. However, objective values in terms of object-groups are more complex. For example, if we would like to know the thermal performance of Office-01, we have to use complex calculations, which may contain several different equations. Hence, there has to be an option for unique equation input. In addition, a manual value input is necessary when the designer does the calculation on paper or using other software. In Fig. 8, an aggregation matrix example shows the method of calculation at a given milestone of a possible project. This matrix always has to be tailored to every project. An arrow shows the direction of the aggregation. If it has multiple starting points, it means it is aggregating those multiple values.

\subsection{Detection of requirement conflicts}

When the values are assigned to objects, we can make a requirement conflict detection. We compare the present performance value to the requirement values, and if the present values satisfy the requirements, then there is no conflict. Otherwise, we detect a conflict. (Fig. 9) In the latter case, the warning marker of the object is set. During the aggregation process, if any of the objects within a category under examination has a warning attribute in the ontological hierarchy, then the examined category will have a warning marker as well. (Fig. 10) The function of conflict detection, which decides whether the result is a clash or not, needs to be set according to the metrics; because in some cases the higher value is the better, in other cases the lower. For example, if the U-value requirement is 0.45 $\mathrm{W} / \mathrm{m}^{2} \mathrm{~K}$, then a lower value will satisfy the requirement; whereas if the sound transmission loss requirement is 35 $\mathrm{dB}$, then a higher value will be satisfactory.

\begin{tabular}{|c|c|c|c|c|}
\hline MILESTONE 2. & Building & Object-group & Objects & \multirow{9}{*}{$\begin{array}{l}\text { DISCIPLINE } \\
\text { AGGREGATION }\end{array}$} \\
\hline Architecture & Average (7) & Average (5) & Average (8) & \\
\hline Interior designer & Average (8) & Average (8) & Man. inp. $(8, .)$. & \\
\hline Cost of interior & N.A. () & N.A. () & N.A. () & \\
\hline Color aesthetics & Average (8) & Average (8) & Man. inp. $(8, .)$. & \\
\hline Architect designer & Average (6) & Average (5) & Average (8) & \\
\hline Accessibility & Man. inp. (7) & Average (3) & Man. inp. $(2, .)$. & \\
\hline Acoustics & Minimum(35dB) & $=\operatorname{Minimum}(35 \mathrm{~dB})$ & Man. inp.(40dB, ..) & \\
\hline \multirow[t]{2}{*}{ Usability } & Average (8) & \begin{tabular}{l|l} 
& Average (8) \\
\end{tabular} & Man. inp. $(8, .)$. & \\
\hline & \multirow{2}{*}{\multicolumn{3}{|c|}{ OBJECT AGGREGATION }} & \\
\hline $\begin{array}{l}\text { N.A. = Not Available } \\
\text { Man. inp. = Manual Input }\end{array}$ & & & & \\
\hline
\end{tabular}

Fig. 8 Aggregation matrix example at a given milestone

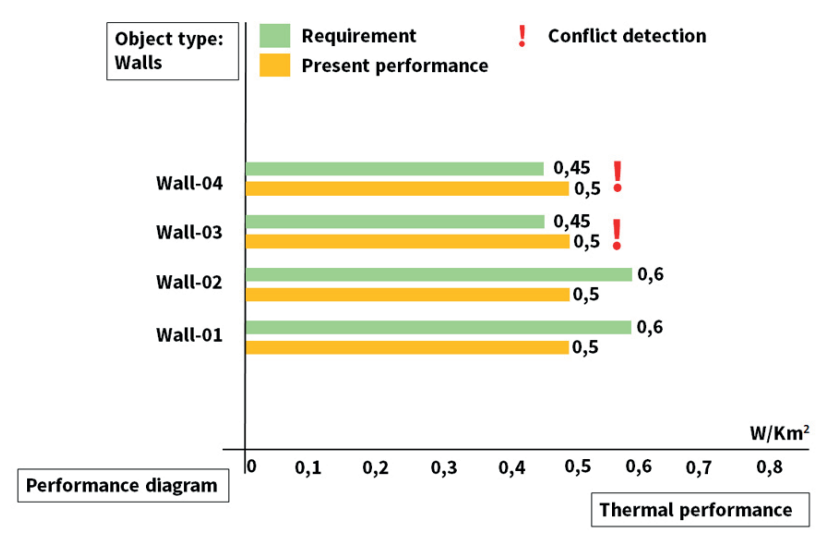

Fig. 9 Conflict detection on object level

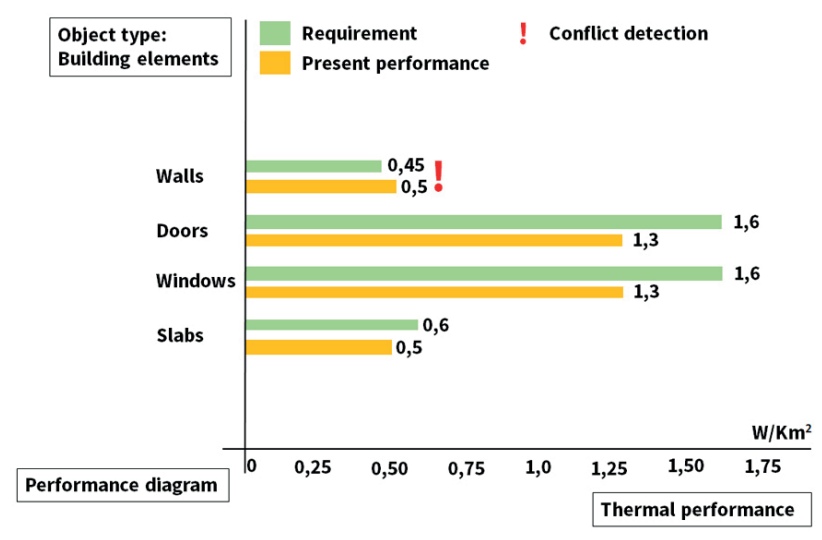

Fig. 10 Conflict detection on building element level 


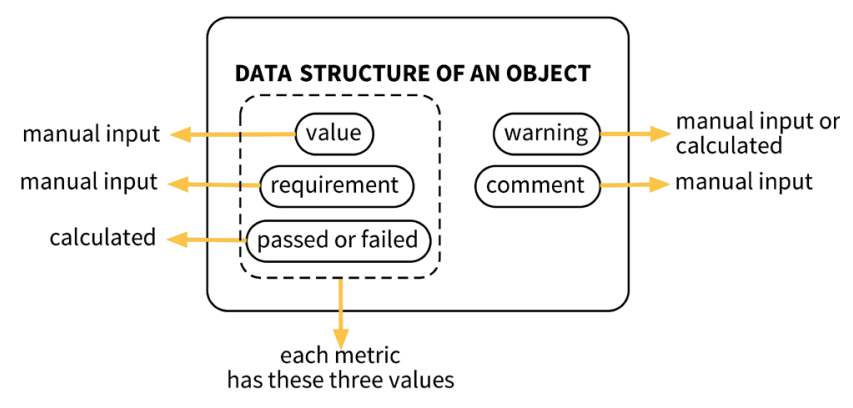

Fig. 11 Datastructure of an object

Zou, Y. et al [8] highlight the fact that handling the rules and regulations manually often resulted in a conflict-ridden and incomplete decision-process. They researched the literature on how automatic rule checking can assist risk management. It turned out that the main principles are similar in both cases: formalize the building code and implement models in the computer programs and execute rule objects over design objects to check compliance automatically.

\section{Object data structure and value input to the building information model}

\subsection{Object data structure}

We represent the meta-information of the objects in the BIM database with a data-schema. (Fig. 11) Each metric has three values: present performance value, requirement value, and pass-or-fail value. The designers manually input the first two. The third depends on the result of conflict detection, whether it passes or fails. An object has a warning marker and a comment value as well. Their purpose is to provide an organized way to communicate and to allow us opportunities to contribute rationale reasons for the object's values to the database.

\subsection{Object value input}

How the discipline designers to the BIM database input the present performance value and the requirement value is an important part of the evaluation process. To test our evaluation method in practice, we came up with the following minimal solution.

Since we believe in open source concepts and that every project participant should have their own free software choice, our focus is on the OPEN BIM environment. In this case, the main data exchange format is IFC. We found that using the IFC description tag to store the discipline-related code is a simple way to solve the task, because we were able to read out the input values and visualize it with Python script. At the same time, this tag gave us freedom in terms of the quality and restrictions of input data.

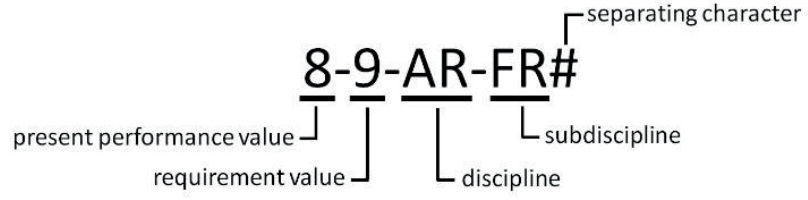

Fig. 12 Suggested code syntax of the discipline-related input values

We created a code syntax to encode the discipline-related values. (Fig. 12) The first value is a floating-point number representing the present performance value. The second value is another floating-point number representing the requirement value. The third value is a 2 -digit string, representing the main discipline category. The fourth value is a 2-digit string as well, representing the sub-discipline category. For separation purposes, we used the "\#" character, since several discipline values can potentially be input one after another.

When the discipline designers decide what present performance values and requirement values to input, they generate the code and input it via CAAD software to the object's IFC description tag.

\section{Ontology of BIM}

During the evaluation method, we had to define concepts - for example, what could be the subject of an evaluation, what kinds of disciplines are present, or what kind of indicator metrics exist. Hence, we needed to use or build a hierarchical ontology that would embrace these notions.

According to our research, other fields in the AEC sector have already used classification systems for cost estimation, construction organization, facility management, etc. There are two widely used classification systems: Uniclass [10] (Table 1) and OmniClass [11]. (Table 2) These systems have several hierarchical lists for the categorization of different concepts - for instance, Disciplines, Tools, Services, Construction Entities, etc.

Table 1 An example of Uniclass classification system

\begin{tabular}{lccc}
\hline Code & Group & Sub group & Title \\
\hline EF_20 & 20 & & Structural elements \\
EF_20_05 & 20 & 05 & Substructure \\
EF_20_10 & 20 & 10 & Frames \\
EF_20_20 & 20 & 20 & Beams \\
EF_20_30 & 20 & 30 & Columns \\
EF_20_50 & 20 & 50 & Bridge abutments \\
EF_25 & 25 & & Wall and barriers \\
EF_25_10 & 25 & 10 & Walls \\
EF_25_30 & 25 & 30 & Doors and windows \\
$\ldots$ & $\ldots$ & $\ldots$ & $\ldots$ \\
\hline
\end{tabular}


Table 2 An example of OmniClass classification system

\begin{tabular}{|c|c|c|}
\hline $23-170000$ & \multicolumn{2}{|c|}{ Openings,Passages, and Protection Products } \\
\hline 23-17 1100 & Doors & \\
\hline $23-171111$ & & Door Components \\
\hline $23-171113$ & & Metal Doors \\
\hline $23-171115$ & & Wood Doors \\
\hline $23-171117$ & & Plastic Doors \\
\hline $23-171119$ & & Composite Doors \\
\hline $23-171121$ & & $\ldots$ \\
\hline $23-171300$ & Windows & \\
\hline $23-171311$ & & Window Components \\
\hline $23-171313$ & & Metal Windows \\
\hline $23-171315$ & & Wood Windows \\
\hline $23-171317$ & & Plastic Windows \\
\hline$\ldots$ & $\ldots$ & $\ldots$ \\
\hline
\end{tabular}

An evaluation method such as ours may use these classification systems, but there will be some cases where it needs to be supplemented. On other occasions, it can be very difficult to adhere to their logic, because these are mainly meant for construction industry or facility management fields.

Another problem with them is that Uniclass is suited to UK industry standards, while Omniclass is suited to US standards, which may differ from the standards from other countries worldwide. Therefore, localization is needed. There are attempts for this on the EU level, according to the European Commission's science and knowledge service at the Joint Research Centre (JRC) [12].

For our evaluation method, we need precise definitions for the following concepts: discipline designers, indicator metrics, and building parts. According to our plan, ontologies being developed in this area will be re-used and extended when they reach sufficient maturity level.

\section{References}

[1] Ács, F., Gáspárdy, B., Porkoláb, F. "Examination of the appliance of BIM in Hungary", presented at BME Scientific Students' Associations Conference, Budapest, Hungary, Nov. 14, 2018. [online] Available at https://tdk.bme.hu/EPK/DownloadPaper/ABIM-hazai-alkalmazasanak-vizsgalata1 [Accessed: 03.04.2019]

[2] Deutsch, R. "Data-Driven Design and Construction: 25 Strategies for Capturing, Analyzing and Applying Building Data" 1st ed., John Wiley \& Sons, Hoboken, New Jersey, United States, 2015.

[3] Kovacs, A. T. "Integrating Object Genesis Information into BIM database", presented at Young Scientist 2017 - 9th International Scientific Conference of Civil Engineering and Architecture, Štrbské Pleso, Kosice, April, 20-21, 2017.

[4] Harding, C. "Integrated Design and Construction - Single Responsibility: A Code of Practice", 1st ed., Wiley-Blackwell, Hoboken, New Jersey, United States, 2015.

\section{Conclusions}

In this article, we made an overview of the present BIM methodology and discovered that there are pain points, which need to be improved in order to increase the productivity of the AEC industry. Hence, we introduced a method for evaluating Building Information Models. This helps decision-makers obtain information about the present status of the building from the points of view of different disciplines.

We gave an example project workflow, in which this method is integrated. We presented the rationale analysis, where all the factors can be taken to account, which effects the evaluation and can be represented visually. We specified the milestones, the discipline designers, the indicator metrics, as well as the subjects of evaluations with ontologies and the aggregation rule. Also, the types of values that designers can input were defined, and the aggregation process was explained through a practical example.

We showed that this method works in theory, and that it is possible to carry it out with present BIM technology. Our current ongoing work is to build a visual analysis tool for BIM models that can be used for the investigation of selected criteria for a building, also by zooming in on specific parts of the building. Finding the best visualization methods requires experimentation and understanding what is easily comprehensible for engineers and project leaders.

Future research directions could be to build a dashboard where the data and the results can be visualized on-the-fly in a simple and efficient way, or to integrate this method with a widely used project management or CAAD system.

[5] Matějkaa, P., Tomek, A. "Ontology of BIM in a Construction Project Life Cycle", Procedia Engineering, 196, pp. 1080-1087, 2017. https://doi.org/10.1016/j.proeng.2017.08.065

[6] Eastman, C., Teicholz, P., Sacks, R., Liston, K. "BIM Handbook: A Guide to Building Information Modeling for Owners, Managers, Designers, Engineers, and Contractors ", 2nd ed., John Wiley \& Sons, Hoboken, New Jersey, United States, 2011.

[7] Fuhr, N., Tsakonas, G., Aalberg, T., Agosti, M., Hansen, P., Kapidakis, S., Klas, C.-P., Kovács, L., Landoni, M., Micsik, A., Papatheodorou, C., Peters, C., Sølvberg, I. "Evaluation of digital libraries", International Journal on Digital Libraries, 8(1), pp. 21-38, 2007. https://doi.org/10.1007/s00799-007-0011-Z

[8] Zou, Y., Kiviniemi, A., Jones, S. W. "A review of risk management through BIM and BIM-related technologies", Safety Science, 97, pp. 88-98, 2017.

https://doi.org/10.1016/j.ssci.2015.12.027 
[9] Succar, B., Bolpagni, M. (eds.) "BIM dictionary", [online] Available at: https://bimdictionary.com [Accessed: 04.04.2019]

[10] Delany, S. "Uniclass 2015", [online] Available at: https://toolkit.thenbs. com/articles/classification\#classificationtables [Accessed: 04.04.2019]

[11] CSI Building Knowledge Improving Project Delivery "OmniClass Construction Classification System", [online] Available at: http:// www.omniclass.org [Accessed: 04.04.2019]
[12] Poljanšek, M. "Building Information Modelling (BIM) standardization", [online] JRC Joint Research Centre, Ispra, Italy, 2017. Available at: http://publications.jrc.ec.europa.eu/repository/bitstream/JRC109656/jrc109656_bim.standardization.pdf [Accessed: 04.04.2019] 